\title{
Placement of shunt reactors in high-voltage network using fuzzy constraints
}

\author{
Arif Hashimov $^{1}$, Huseyngulu Guliyev ${ }^{1, *}$, Aytek Babayeva ${ }^{1}$ \\ ${ }^{1}$ Azerbaijan Scientific-Research and Designed-Prospecting Institute of Energetics, Baku, Azerbaijan
}

\begin{abstract}
In recent years, controlled shunt reactors (CSR) relevant to the class of FACTS facilities have been widely used to control voltage modes and reactive power flows in the high-voltage electrical network. The selection of location, as well as the definition of the law of CSR control in the conditions of stochastic variability of the operation mode of high-voltage power transmission, are associated with numerous technical and economic factors. At the same time, such constraint conditions as ease of use, performance efficiency, purpose and location in the system, as well as the period of commissioning should be taken into account. In the proposed procedure these factors are considered as fuzzy constraints. The procedure of CSR placement in the $330 \mathrm{kV}$ electrical network of Azerenergy system for control of reactive power flows taking into account the mentioned fuzzy constraints is proposed. The obtained simulation results confirm the advantage of the proposed procedure.
\end{abstract}

\section{Introduction}

In the modern period in the power systems of CIS and foreign countries, great importance is attached to the creation of controlled or flexible power lines, which are part of "smart" networks (Smart Grid) with FACTS facilities [1]. For the optimal control of the modes of such power systems, there is a need for highly efficient means of control of the flows of both active and reactive powers.

To control the voltage and reactive power regimes, in addition to the generators, synchronous and static compensators, switching reactors and capacitor banks, new facilities - controlled shunt reactors (CSR) - have been widely used in recent decades [2-6]. The economic analyses have shown that additional energy losses are at such a high level that despite the availability of expensive equipment, the CSR installation is self-supporting for a period of less than 5 years [7]. There is still the problem of elimination of the surplus reactive power generated in the minimum load modes in most power grids. The main reason for this redundancy is that the charging power in $330 \mathrm{kV}$ lines is higher than the reactive power loss in them, and this can cause the voltage level increase to a level dangerous for the line insulation.

Traditional methods and means used in the modern period to eliminate surplus reactive power are not effective enough and should be replaced by more modern technological means.From this point of view, $330 \mathrm{kV} \mathrm{CSR}$ is preferable. Thus, the "reactive power loss -charging power" relation in the networks is not constant, it changes. Therefore, to ensure the balance of reactive powers, the CSR power must be controled in a wide range [8].
During the selection of power and the CSR installation location, as well as changes in the operating mode of power transmission, the definition of the control mode is associated with numerous economic and technical factors.So, the installation location and the CSR characteristics affect the energy losses in the entire power transmission, the mode stability, ensuring voltage regulation within the predetermined limits during various power transmissions, the formation of excess voltages in individual elements of the power transmission. At the same time, other factors should also be taken into account during the CSR selection, such as the convenience of the CSR installation place in the given point of the network from the point of view of operation, operating efficiency, technical and economic indicators. So, for different networks these or other factors are an acceptable option for the selection and placement of compensating devices.

In the conditions of numerous influencing factors, the choice of compensating means, determination of the optimal option taking into account the specified practical cases leads to the solution of the multipurpose problem. Thus, the solution of this problem without the use of modern mathematical technologies is extremely complicated.

In the present paper the problems of selection and placement of $330 \mathrm{kV}$ controlled shunt reactors on the basis of studies conducted on real perspective scheme of the power system are considered.

\section{CSR placement in $330 \mathrm{kv}$ nodes of power grid}

\footnotetext{
*Corresponding author: huseyngulu@mail.ru
} 
A special procedure can be used for the reactor placement in the power system. In order to determine the criteria for selection of the most efficient CSR installation locations, it is necessary to analyze their impact on two important indicators of the power system mode. It is known that such indicators are the values of absolute and relative reduction of voltage levels at various points of the network before and after the reactor installation, as well as the values of losses in the network. Calculations should be carried out for the most severe minimum load conditions, so that the voltage levels at the observed points of the network reach the maximum possible value. Obviously, in this mode the reactor power should be maximal. Therefore, during the comparative calculations, the CSR power is assumed to be equal to the reactor rated power for all nodes.

Placement of a single CSR at separate substations will impact differently on the average voltage level in $330 \mathrm{kV}$ nodes of power system and the total loss level in networks.Obviously, the CSR installation at any substation will lower the voltage level both at this station (most of all) and at other substations. Therefore, the average undervoltage can be accepted as the main technical efficiency indicator of the reactor installation. Another important indicator is the power loss reduction in networks. It should be noted that during the installation of a single CSR, in contrast to the voltage, the power loss can both increase and decrease.

Taking into account the above-mentioned, as a special technical efficiency indicator of the reactor installation, the mean absolute $\delta U_{o r}$, mean relative $\delta \bar{U}_{o r}$ voltage reduction and, accordingly, the absolute $\delta P_{\Sigma}$ and relative $\delta \bar{P}_{\Sigma}$ total power loss reduction can be accepted. These quantities can be determined by performing multivariate calculations with the alternate CSR placement at different substations. In addition to the above, for a comprehensive assessment of the technical and economic efficiency of the CSR application, the resulting efficiency indicator $E_{e f, \Sigma}$ was proposed, which is expressed as follows [2]:

$$
E_{e f, \Sigma}=\delta \bar{U}_{o r} \cdot \delta \bar{P}_{\Sigma}
$$

It is possible to advance an idea of comparative efficiency of the CSR installation at different points of the network in accordance with the value of this indicator.It should be noted that in the case when the CSR placement has the same effect on the average voltage level (it always reduces), the reactor loss level is double affected.

Table 1. Efficiency indicator values for $330 \mathrm{kV}$ nodes of power grid

\begin{tabular}{|c|c|c|c|c|c|c|c|c|c|}
\hline \multirow[t]{2}{*}{$\begin{array}{c}\text { Node } \\
\text { No. }\end{array}$} & \multirow{2}{*}{ Node name } & \multicolumn{2}{|c|}{ Voltage, kV } & \multirow{2}{*}{$\begin{array}{l}\text { Total } \\
\text { losses } \\
\text { in the } \\
\text { networ } \\
\mathbf{k}, \mathrm{MW}\end{array}$} & \multicolumn{2}{|c|}{$\begin{array}{c}\text { Absolute and } \\
\text { relative } \\
\text { decrease of } \\
\text { total losses }\end{array}$} & \multicolumn{2}{|c|}{$\begin{array}{c}\text { Average } \\
\text { absolute and } \\
\text { relative } \\
\text { voltage }\end{array}$} & \multirow{2}{*}{$\begin{array}{c}\begin{array}{c}\text { Efficien } \\
\text { cy } \\
\text { factor, }\end{array} \\
E_{e f}\end{array}$} \\
\hline & & $\begin{array}{l}\text { Bus voltage } \\
\text { before the } \\
\text { SR } \\
\text { connection }\end{array}$ & $\begin{array}{l}\text { Average } \\
\text { voltage after } \\
\text { SR } \\
\text { connection }\end{array}$ & & MW & $\%$ & $\mathrm{kV}$ & $\%$ & \\
\hline 39 & Absheron 330 & 344,38 & 334,23 & 14,5 & 0,7 & 4,61 & 3,60 & 1,07 & 4,912 \\
\hline 201 & Janub PP & 346,53 & 334,66 & 14,6 & 0,6 & 3,94 & 3,17 & 0,94 & 3,701 \\
\hline 101 & Yashma 330 & 342,18 & 333,96 & 14,9 & 0,3 & 1,97 & 3,87 & 1,15 & 2,261 \\
\hline 601 & Mini HPP & 339,44 & 335,55 & 14,7 & 0,5 & 3,29 & 2,41 & 0,71 & 2,349 \\
\hline 651 & AzES330 & 339,23 & 335,55 & 14,7 & 0,5 & 3,29 & 2,28 & 0,68 & 2,219 \\
\hline 400 & Goranboy SG & 338,76 & 334,91 & 14,9 & 0,3 & 1,97 & 2,92 & 0,86 & 1,704 \\
\hline 333 & Agdjabedi330 & 342,64 & 333,78 & 15,0 & 0,2 & 1,32 & 4,05 & 1,19 & 1,577 \\
\hline 280 & Imishli 330 & 344,27 & 333,86 & 15,0 & 0,2 & 1,32 & 3,97 & 1,18 & 1,548 \\
\hline 801 & Khachmaz330 & 343,43 & 333,99 & 15,0 & 0,2 & 1,32 & 3,84 & 1,14 & 1,497 \\
\hline 411 & Shamkir HPP & 331,01 & 336,13 & 15,4 & $-0,2$ & $-1,32$ & 1,70 & 0,50 & $-0,663$ \\
\hline 401 & Gandja330 & 329,82 & 335,79 & 15,5 & $-0,3$ & $-1,97$ & 2,04 & 0,60 & $-1,190$ \\
\hline 456 & Samukh 330 & 328,74 & 335,98 & 15,6 & $-0,4$ & $-2,63$ & 1,85 & 0,55 & $-1,443$ \\
\hline 457 & GAZ 330 & 328,28 & 335,89 & 15,8 & $-0,6$ & $-3,95$ & 1,94 & 0,58 & $-2,269$ \\
\hline 502 & Agstafa 330 & 330,89 & 335,25 & 15,9 & $-0,7$ & $-4,61$ & 2,58 & 0,76 & $-3,516$ \\
\hline
\end{tabular}

Thus, in this case the loss may both increase (useful effect) and decrease (useless effect). Obviously, in this case, the comparison and alternation of substations according to the $E_{e f, \Sigma}$ indicator gives meaning to its positive values. In other words, certain places for the CSR installation should be selected among the nodes with the $E_{e f, \Sigma}>0$ condition. In addition, other factors should be taken into account, especially the periods of commissioning of substations, the availability of place for CSR installation, possibility of reactive power flows from neighboring power systems.
The values of the special and resultant efficiency indicators for the $330 \mathrm{kV}$ nodes of the power system (initial loss of 15.2 MW) are given in Table 1. The nodes are arranged in a sequence of decreasing values of $E_{e f, \Sigma}$ indicator.

As can be seen from the table, the $E_{e f, \Sigma}$ value is positive only for 9 nodes of the considered 14 ones, and the reactor installation locations should be selected between the nodes just with this value $E_{e f, \Sigma}>0$. In this case, in addition to the condition $E_{e f, \Sigma}>0$, as noted 
above, other factors should be taken into account (the periods of commissioning of substations, the availability of places for the SR installation, the technical possibility for the electric schematic diagram of switchgear, etc.).

\section{Taking into account of constraints during sr placement}

The other 5 factors influencing the selection of SR installation place were taken into account in the form of fuzzy constraints: the period of commissioning of substation; the period of the substation operation; the availability of the installation place; the possibility of an electrical wiring diagram; the substation place in the system. For linguistic variables the membership functions of Gauss, type $\mathrm{Z}$ and $\mathrm{S}$ were accepted.

Gauss membership function:

$$
\mu_{k i}(x)=\exp \left(\frac{-\left(x_{i}-m_{k i}\right)}{2 \sigma_{k i}{ }^{2}}\right), \quad i=\overline{1, n} \quad k=\overline{1, m}
$$

where $m$ - coordinate of the maximum; $\sigma-$ concentration ratio.

$z m f$ and $s m f-$ membership function

$$
\mu_{k i}(x)= \begin{cases}1, & x_{i} \leq a_{k i} \\ \text { nonlinearapproximation, }, & a_{k i}<x_{i}<b_{k i} \\ 0, & x_{i} \geq b_{k i}\end{cases}
$$

where $m-$ coordinate of the maximum; $\sigma-$ concentration ratio; $a, d$ - fuzzy set carrier; $b, c$ - fuzzy set kernel, $\mu_{A, i}(x): X_{i} \rightarrow[0,1]$.

After determination of forms of fuzzy implication and membership functions, the output signals were formed on the basis of fuzzy approximation between the input and output vectors.

$$
\mu_{A, i}(x): X_{i} \rightarrow[0,1]
$$

The membership functions of input and output variables and their terms are shown in Fig.1, and their parameters - in Table 2 .
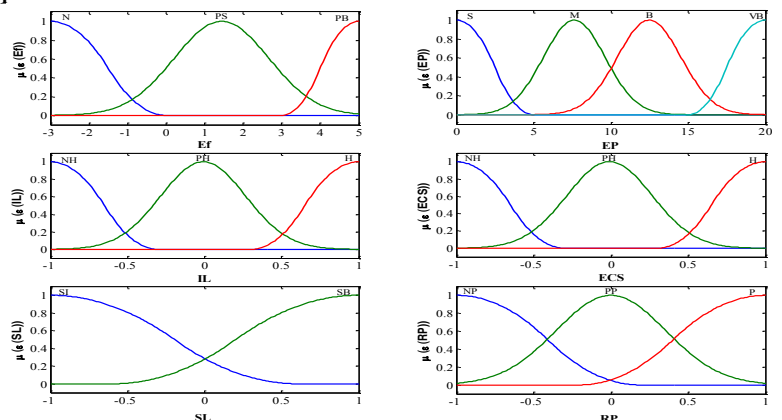

Fig. 1. Membership function of terms of linguistic variables

\begin{tabular}{|c|c|c|}
\hline Term-subsets & $\begin{array}{c}\text { Membership } \\
\text { functions }\end{array}$ & Parameters \\
\hline \multicolumn{3}{|c|}{ Efficiency factor, EF } \\
\hline Negative $(\mathrm{N})$ & $\mathrm{Zmf}$ & {$\left[\begin{array}{ll}-3 & 0\end{array}\right]$} \\
\hline Positive small (PS) & Gaussmf & {$\left[\begin{array}{ll}1,23 & 1,44\end{array}\right]$} \\
\hline Positive big (PB) & Smf & {$\left[\begin{array}{ll}3 & 5\end{array}\right]$} \\
\hline \multicolumn{3}{|c|}{ Commissioning period, EP } \\
\hline Small (S) & $\mathrm{Zmf}$ & {$\left[\begin{array}{ll}0 & 5\end{array}\right]$} \\
\hline Mean (M) & Gaussmf & {$[2,7,62]$} \\
\hline Big (B) & Gaussmf & {$[2,07 \quad 12,47]$} \\
\hline Very big (VB) & Smf & {$[14,97 \quad 20]$} \\
\hline \multicolumn{3}{|c|}{ Installation places, IL } \\
\hline No (NH) & $\mathrm{Zmf}$ & {$\left[\begin{array}{ll}-1 & -0,3\end{array}\right]$} \\
\hline Частично есть (РН) & Gaussmf & {$[0,277 \quad-0,009]$} \\
\hline Есть $(\mathrm{H})$ & Smf & {$[0,31]$} \\
\hline \multicolumn{3}{|c|}{ Connection diagram, ECS } \\
\hline Нет $(\mathrm{NH})$ & $\mathrm{Zmf}$ & {$\left[\begin{array}{ll}-1 & -0,3\end{array}\right]$} \\
\hline Partially available $(\mathrm{PH})$ & Gaussmf & {$[0,277-0,009]$} \\
\hline Available $(\mathrm{H})$ & Smf & {$[0,31]$} \\
\hline \multicolumn{3}{|c|}{ Places in the system, SL } \\
\hline Backbone, SI & $\mathrm{Zmf}$ & {$\left[\begin{array}{ll}-1 & 0,607]\end{array}\right.$} \\
\hline Between systems, SB & Smf & {$\left[\begin{array}{ll}-0,6 & 1\end{array}\right]$} \\
\hline \multicolumn{3}{|c|}{ Reactor installation, $\mathbf{R P}$} \\
\hline Don’t install (MP) & $\mathrm{Zmf}$ & {$\left[\begin{array}{ll}-1 & 0,18\end{array}\right]$} \\
\hline Partially possible (PP) & Gaussmf & {$[0,350]$} \\
\hline To install $(\mathrm{P})$ & Smf & {$\left[\begin{array}{ll}-0.2 & 1\end{array}\right]$} \\
\hline
\end{tabular}

Table 2. Terms of linguistic variables, membership functions and their parameters

Fuzzy output mechanism consisting of 65 rules synthesized based on the Mamdani algorithm is shown in Fig.2.

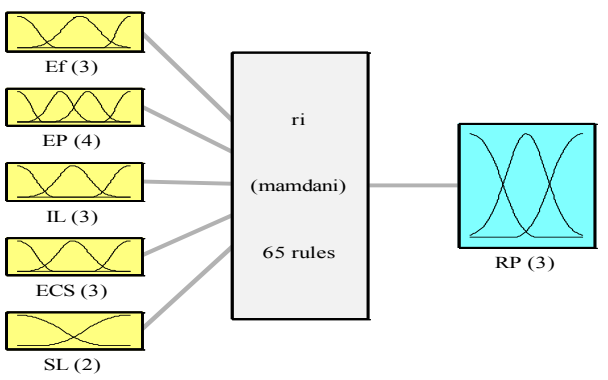

Fig. 2. Fuzzy logic output mechanism

The decision-making procedure for one option according to the given rules is shown in Fig.3.

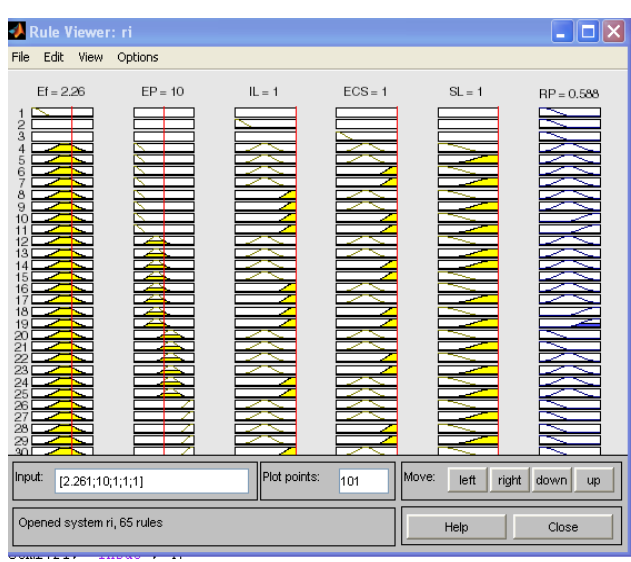

Fig. 3. Decision-making procedure segment 


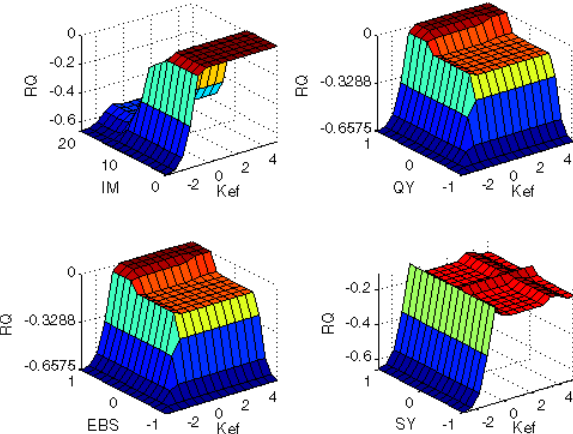

Fig. 4. Fuzzy surface dependences
The "indicated surfaces - output variables" relationships (SR installation node) taking into account fuzzy constraints are presented in Fig.4. Table 3 presents the results of the adjustment of the priority nodes according to this procedure.

Table 3. Efficiency factor values for $330 \mathrm{kV}$ nodes

\begin{tabular}{|c|c|c|c|c|c|c|c|c|c|c|}
\hline \multirow{2}{*}{$\begin{array}{l}\text { Node } \\
\text { No. }\end{array}$} & \multirow{2}{*}{ Node name } & \multicolumn{2}{|c|}{ Voltage, $\mathrm{kV}$} & \multirow{2}{*}{$\begin{array}{c}\text { Total } \\
\text { losses in } \\
\text { network } \\
\text {, MW }\end{array}$} & \multicolumn{2}{|c|}{$\begin{array}{l}\text { Absolute and } \\
\text { relative decrease } \\
\text { of total losses }\end{array}$} & \multicolumn{2}{|c|}{$\begin{array}{c}\text { Average } \\
\text { absolute and } \\
\text { relative voltage } \\
\text { decrease }\end{array}$} & \multirow{2}{*}{$\begin{array}{c}\text { Efficienc } \\
\text { y factor, } \\
E_{e f}\end{array}$} & \multirow{2}{*}{$\begin{array}{c}\text { Reactor } \\
\text { installat } \\
\text { ion } \\
\\
\\
R P\end{array}$} \\
\hline & & $\begin{array}{l}\text { Bus voltage } \\
\text { before SR } \\
\text { connection }\end{array}$ & $\begin{array}{l}\text { Average } \\
\text { voltage after } \\
\text { SR } \\
\text { connection } \\
\end{array}$ & & MW & $\%$ & $\mathrm{kV}$ & $\%$ & & \\
\hline 400 & Goranboy SG & 338,76 & 334,91 & 14,9 & 0,3 & 1,97 & 2,92 & 0,86 & 1,704 & 0,518 \\
\hline 201 & Janub PP & 346,53 & 334,66 & 14,6 & 0,6 & 3,94 & 3,17 & 0,94 & 3,701 & 0,508 \\
\hline 101 & Yashma 330 & 342,18 & 333,96 & 14,9 & 0,3 & 1,97 & 3,87 & 1,15 & 2,261 & 0,172 \\
\hline 280 & Imishli 330 & 344,27 & 333,86 & 15,0 & 0,2 & 1,32 & 3,97 & 1,18 & 1,548 & 0,015 \\
\hline 801 & Khachmaz 330 & 343,43 & 333,99 & 15,0 & 0,2 & 1,32 & 3,84 & 1,14 & 1,497 & 0,014 \\
\hline 333 & Agdjabedi 330 & 342,64 & 333,78 & 15,0 & 0,2 & 1,32 & 4,05 & 1,19 & 1,577 & 0,013 \\
\hline 456 & Samukh 330 & 328,74 & 335,98 & 15,6 & $-0,4$ & $-2,63$ & 1,85 & 0,55 & $-1,443$ & $-0,434$ \\
\hline 411 & Shamkir HPP & 331,01 & 336,13 & 15,4 & $-0,2$ & $-1,32$ & 1,70 & 0,50 & $-0,663$ & $-0,536$ \\
\hline 601 & Mini HPP & 339,44 & 335,55 & 14,7 & 0,5 & 3,29 & 2,41 & 0,71 & 2,349 & $-0,551$ \\
\hline 651 & AzES 330 & 339,23 & 335,55 & 14,7 & 0,5 & 3,29 & 2,28 & 0,68 & 2,219 & $-0,551$ \\
\hline 401 & Gandja 330 & 329,82 & 335,79 & 15,5 & $-0,3$ & $-1,97$ & 2,04 & 0,60 & $-1,190$ & $-0,558$ \\
\hline 457 & GAZ 330 & 328,28 & 335,89 & 15,8 & $-0,6$ & $-3,95$ & 1,94 & 0,58 & $-2,269$ & $-0,631$ \\
\hline 502 & Agstafa 330 & 330,89 & 335,25 & 15,9 & $-0,7$ & $-4,61$ & 2,58 & 0,76 & $-3,516$ & $-0,658$ \\
\hline 39 & Absheron 330 & 344,38 & 334,23 & 14,5 & 0,7 & 4,61 & 3,60 & 1,07 & 4,912 & $-0,658$ \\
\hline
\end{tabular}

As can be seen, taking into account these factors, the priority nodes are Goranboy SG, Janūb ES, Yashma $330 \mathrm{kV}$, Imishli SS and Khachmaz $330 \mathrm{kV}$. Thus, if we take into account the situation in the system and the calculation results, then initially the Yashma $330 \mathrm{kV}$ and $330 \mathrm{kV}$ SG Goranboy nodes can be accepted. So, for both nodes the condition $E_{e f, \Sigma}>0$ is met and in addition, due to the ability to connect the reactor to busbar at the Yashma $330 \mathrm{kV}$ Substation and one circuit of one-and-a-half scheme on $330 \mathrm{kV} \mathrm{SG}$ Goranboy to a free node, and due to the availability of appropriate places for the reactor placement, the schemes turn out efficient and reliable.

As can be seen from the Table 1 , the $330 \mathrm{kV}$ Goranboy ES buses and $330 \mathrm{kV}$ Imishli nodes can be considered as pretenders for the third node for the reactor connection in the future.

\section{Simulation results}

To determine the voltage levels in the nodes of the power system, the corresponding mode calculations for the maximum and minimum load should be carried out.
The voltage profiles of some characteristic load nodes with voltage of 330 and $500 \mathrm{kV}$ based on calculations performed for the maximum and minimum load modes in real perspective schemes of the power system are shown in Fig.5.

It should be noted that the maximum load regime of the power system was formed according to the data obtained from "Perspective development scheme" Department of "AzRandDSIPE"JSC. And minimum load mode was adopted 0.3 Pmax (Pmax - the maximum active load of the power system).

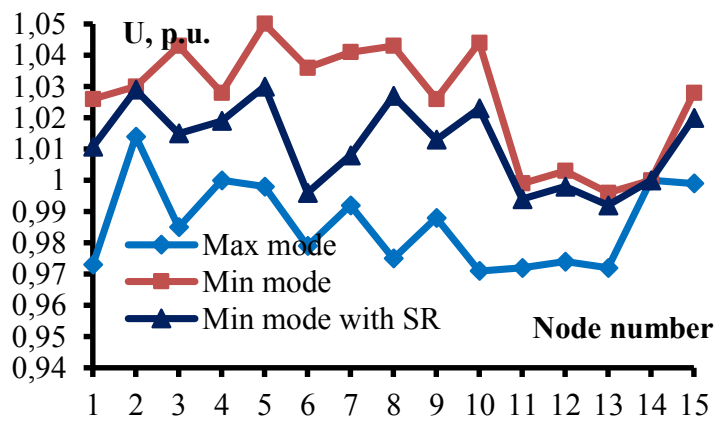

Fig.5.Voltage profiles in $330,500 \mathrm{kV}$ nodes for normal modes of power grid 
As can be seen from the figure, in the maximum load mode ( $\mathrm{Py}=5613.9 \mathrm{MW}, \mathrm{Qt}=3355.2 \mathrm{MVAr})$ the voltage in $500 \mathrm{kV}$ nodes varies within the (1.0$1.014)$ Unom interval, in $330 \mathrm{kV}$ nodes within the (0.972-0.999)Unom interval, and in the minimum mode $(\mathrm{Py}=1684.2 \mathrm{MW}, \mathrm{Qt}=1006.6 \mathrm{MVAr})$ the voltage in $500 \mathrm{kV}$ nodes varies within the (1.0-1.03)Unom interval, in $330 \mathrm{kV}$ nodes within the (0.996-1.05)Unom interval (Table 3 ). Thus, the voltage in the maximum and minimum modes is within normal limits. In some nodes, the voltage is set to the upper limit.

Taking into account the above, the calculation was repeated for the minimum load mode with the connection of a shunt reactor with a capacity of 180 MVAr to the node Goranboy $330 \mathrm{kV}$, and the reactor with a capacity of 100 MVAr to the node Yashma 330 $\mathrm{kV}$. As can be seen, in the case of the reactor connection, the voltage profiles in the minimum load mode improve and change within the range $(0.992-$ 1.03)of Unom around the nominal value.

Table 4. Voltage variation limits in 500 and $330 \mathrm{kV}$ nodes

\begin{tabular}{|c|c|c|c|c|}
\hline Modes & \multicolumn{2}{|c|}{ Load } & \multicolumn{2}{c|}{ Voltage variation interval } \\
\hline- & $\begin{array}{c}\mathrm{P}, \\
\mathrm{MW}\end{array}$ & $\begin{array}{c}\mathrm{Q}, \\
\text { MVAr }\end{array}$ & $500 \mathrm{kV}$ & $330 \mathrm{kV}$ \\
\hline $\begin{array}{c}\text { Maximal } \\
\text { mode }\end{array}$ & 5613,9 & 3355,2 & $\begin{array}{c}(1,0- \\
1,014) \mathrm{U}_{\text {nom }}\end{array}$ & $\begin{array}{c}(0,972- \\
0,999) \mathrm{U}_{\text {nom }}\end{array}$ \\
\hline $\begin{array}{c}\text { Minimal } \\
\text { mode }\end{array}$ & 1684,2 & 1006,6 & $\begin{array}{c}(1,0- \\
1,03) \mathrm{U}_{\text {nom }}\end{array}$ & $\begin{array}{c}(0,996- \\
1,05) \mathrm{U}_{\text {nom }}\end{array}$ \\
\hline $\begin{array}{c}\text { Minimal } \\
\text { mode after } \\
\text { reactor } \\
\text { connection }\end{array}$ & 1684,2 & 1006,6 & & $\begin{array}{c}(0,992- \\
1,03) \mathrm{U}_{\text {nom }}\end{array}$ \\
\hline
\end{tabular}

At the next stage the calculations were performed with the simulation of emergency modes according to the criteria $\mathrm{N}-1$ and $\mathrm{N}-2$. The cases of disconnection of lines Absheron-1, Absheron-8, Agstafa-4, Goranboy-3, Shimal ES according to criterion N-1, and disconnections of lines Shimal ES and Absheron-1 according to criterion $\mathrm{N}-2$ were considered.

Voltage profiles in the nodes based on the results of calculations performed according to the $\mathrm{N}-1$ criterion are presented in Fig.6.

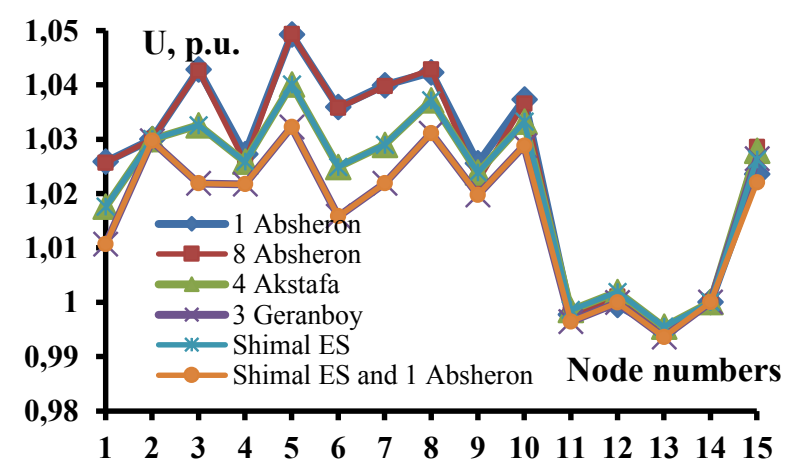

Fig. 6. Voltage profiles for emergency modes

As can be seen in Fig.6, model calculations in emergency modes of power system based on the N-1 criterion indicate the voltage location at the nodes within acceptable limits. The voltage in some nodes, for example, the voltage in the $5^{\text {th }}$ node (Janub ES) during the disconnection of Absheron-8, Agstafa-4 and Goranboy-3 lines is in the upper limit. The same conclusion can be drawn with respect to the Imishli node. Taking this into account, mode calculations were carried out for the case of connection of shunt reactors to certain nodes in some of the considered emergency modes (disconnection of the Agstafa-4 and Goranboy-3 lines).

\section{Conclusions}

1. In order to control the reactive power flows in the power system, the procedure of selection and placement of CSR devices in $330 \mathrm{kV}$ nodes with fuzzy constraints is proposed.

2. On the basis of the developed procedure, priority nodes for the CSR placement in the Azerenergy system were identified. The mode calculations with the CSR placement in these nodes are carried out. The results confirmed a significant improvement of the voltage profile at the nodes.

\section{References}

1. Dolgopolov A.G., Condratenko D.V., Ucolov S.V., Postolati V.M. Reactoare controlate shuntate pentru retele electrice. Problemele Energeticii Regionale, 3(17), 2011, c.1-21.

2. Dolgopolov A.G. Bias-controlled shunt reactors. Operation speed issues // News of Electrical Engineering, No.4(64), 2010, Electronic resource.

3. Bryantsev M.A., Lurie A.I., Spiridonov D.Y. Results of introduction of bias-controlled shunt reactors in 110-500 kV networks // Electro, No.3, 2006, pp.25-31.

4. Kochkin V.I., Nechaev O. P. Application of static reactive power compensators in electrical networks of power systems and enterprises.-M., Publishing house of SC ENAS, 2002, pp.248.

5. Hashimov A.M., Guliyev H.B., Babayeva A.R. IJTPE Journal International Journal on technical and physical problems of engineering (IJTPE), Issue 30, Vol. 9, No. 1, 2017, pp.18-22.

6. Hashimov A.M., Guliyev H.B., Babaeva A.R. Selection and placement of compensating devices of the excess reactive power in high-voltage electrical networks // Problems of Power Engineering, No.1, 2019, pp.3-12.

7. Controlled bias electric reactors, ed. by Bryantsev A. M., ZNAK, 2010, p.288.

8. Hashimov A.M., Guliev H.B., Babayeva A.R. Multi-pole fuzzy logic controller to improve the control of shunt reactors // Electricity, No. 6, 2019, pp. 26-32. 